\title{
Long-term effects of Youth Mental Health First Aid training: randomized controlled trial with 3-year follow-up
}

Amy J. Morgan 1* 1 , Julie-Anne A. Fischer ${ }^{1}$, Laura M. Hart ${ }^{1,2}$, Claire M. Kelly ${ }^{3}$, Betty A. Kitchener ${ }^{3,4}$, Nicola J. Reavley ${ }^{1}$, Marie B. H. Yap ${ }^{1,5}$ and Anthony F. Jorm ${ }^{1}$

\begin{abstract}
Background: Mental Health First Aid (MHFA) training teaches community members how to provide initial support to someone with a mental health problem. Key gaps in the evidence base supporting the training are the longevity of effects beyond 6 months, effects on mental health first aid behavior, and the impact of support on the recipient of aid. This study aimed to evaluate the effect of the Youth MHFA course 3 years after training.

Methods: 384 Australian parents of an adolescent aged 12-15 were randomized to receive either the 14-h Youth MHFA course or the 15-h Australian Red Cross Provide First Aid course. This paper reports outcomes at baseline and 3 years later. Primary outcomes were cases of adolescent mental health problems, and parental support towards their adolescent if they developed a mental health problem, rated by the parent and adolescent. Secondary outcomes included parent knowledge about youth mental health problems, intentions and confidence in supporting a young person, stigmatizing attitudes, and help-seeking for mental health problems. Data were analyzed with mixed-effects models with group by measurement occasion interactions.
\end{abstract}

Results: 3-year follow-up data was obtained from 149 parents and 118 adolescents, who were aged 16.5 years on average. Between baseline and 3-year follow-up, there was a non-significant reduction in adolescent cases of mental health problems relative to the control group (odds ratios (OR) 0.16-0.17), a non-significant improvement in parental support reported by adolescents with a mental health problem (OR 2.80-4.31), and a non-significant improvement in the quality of support that parents reported providing to their adolescents with a mental health problem $(d=0.38)$. Secondary outcomes that showed significant improvements relative to the control group were parental knowledge about youth mental health problems $(\mathrm{d}=0.31)$ and adolescent perceptions of general social support from their parents $(\mathrm{d}=0.35)$.

Conclusions: This paper reports on the longest follow-up of Mental Health First Aid training in a controlled trial. Three years after training, participants had maintained their improved knowledge about mental health problems. There were some indications of other positive effects, but the study was underpowered to clearly show benefits to mental health first aid skills and recipients of aid.

(Continued on next page)

\footnotetext{
*Correspondence: ajmorgan@unimelb.edu.au

${ }^{1}$ Centre for Mental Health, Melbourne School of Population and Global

Health, University of Melbourne, 207 Bouverie Street, Melbourne, Victoria 3010, Australia

Full list of author information is available at the end of the article
}

(c) The Author(s). 2020 Open Access This article is licensed under a Creative Commons Attribution 4.0 International License, which permits use, sharing, adaptation, distribution and reproduction in any medium or format, as long as you give appropriate credit to the original author(s) and the source, provide a link to the Creative Commons licence, and indicate if changes were made. The images or other third party material in this article are included in the article's Creative Commons licence, unless indicated otherwise in a credit line to the material. If material is not included in the article's Creative Commons licence and your intended use is not permitted by statutory regulation or exceeds the permitted use, you will need to obtain permission directly from the copyright holder. To view a copy of this licence, visit http://creativecommons.org/licenses/by/4.0/. The Creative Commons Public Domain Dedication waiver (http://creativecommons.org/publicdomain/zero/1.0/) applies to the data made available in this article, unless otherwise stated in a credit line to the data. 
(Continued from previous page)

Trial registration: ACTRN12612000390886, registered retrospectively 5/4/2012, https://www.anzctr.org.au/Trial/ Registration/TrialReview.aspx?id=347502

Keywords: Mental health first aid, Social support, Help-seeking behavior, Mental disorders, Adolescent, Parent

\section{Background}

Mental Health First Aid (MHFA) is a training program that teaches community members how to provide initial support to people with mental health problems. MHFA training was developed because members of the public often have poor mental health literacy, possess stigmatizing attitudes, and lack the confidence and knowledge of how to help a person with a mental health problem [1]. Yet friends and family are often the first people who can provide assistance and facilitate professional help. MHFA teaches people how to assist those who are developing a mental health problem, experiencing a worsening of an existing mental health problem or are in a mental health crisis. The course is analogous to physical first aid, where aid is given until professional help is received or the crisis resolves. There are core MHFA courses to assist specific population groups (e.g. adults, youth, older people), and specialized courses teaching how to help someone experiencing a specific crisis or situation, such as suicidal thoughts and behaviors [2]. MHFA training began in Australia in 2000 and has had a global impact, spreading to over 27 countries with more than 3 million people trained worldwide [3].

One factor in MHFA's successful dissemination has been its commitment to evidence-based training and strong research focus [4]. Training courses are based on guidelines on how to provide mental health first aid that are developed using expert consensus studies [5]. Key elements of the guidelines are summarized in a 5-point MHFA Action Plan taught in the course. MHFA courses are also regularly revised to incorporate new research, such as updated guidelines on how to provide mental health first aid (e.g. [6]). There has also been a strong emphasis on rigorous evaluation of courses. There have been at least 18 controlled trials of MHFA courses, conducted by different investigators around the world [7]. These evaluations have demonstrated improved knowledge about mental health problems and treatments, reduced stigma, and improved confidence and intended support towards people with mental health problems or in crisis. A smaller number of trials have also shown increased help offered to someone with a mental health problem [8-10]. While these findings provide support for the program's benefits, there are some key evidence gaps. Few studies have investigated outcomes more than 6 months after training, so the longevity of the above effects is unclear. Furthermore, recent reviews [7, 11, 12] have highlighted that there is weak evidence supporting improved mental health first aid behavior, and few studies have investigated the effects upon the recipient of mental health first aid, rather than trainees. These effects include perceived support from the first aider, mental health service use, and improvements in mental health.

The Training for Parents of Teenagers randomized controlled trial was designed to address key limitations in the evidence base of the MHFA program. The trial aimed to investigate the long-term effects of the training and its impact upon the recipient of aid. Parents of early adolescents were trained in Youth Mental Health First Aid, and effects upon their teenage children were investigated. The training was delivered during adolescence, a critical period when mental health problems often first develop and mental health first aid could therefore be offered [13]. The use of an active control condition (physical first aid training) meant that effects could be assessed several years after training, which is impossible to do with a waitlist control design. We have already reported outcomes from the trial at 1-year and 2-year follow-up [14], which showed improvements in mental health literacy in training recipients relative to the control. For example, increased parental knowledge about youth mental health problems $(\mathrm{d}=0.43$ at 1 -year and $\mathrm{d}=0.26$ at 2-year), and increased confidence to help a young person $(\mathrm{d}=0.26)$ and intentions to provide effective support $(d=0.22)$ at 1-year follow-up. However, effects on the recipient of aid were less clear. The number of adolescents with a mental health problem during follow-up was too small to provide certainty about the effects of the training. There were very small, nonsignificant differences in the quality of parental support, favoring the MHFA group ( $\mathrm{ds}=0.16-0.17$ ). Additionally, although the proportion of adolescents with a mental health problem dropped in the MHFA group but remained similar in the control group, the study was underpowered to detect a difference.

This paper reports on 3-year follow-up outcomes from the Training for Parents of Teenagers study. This is the longest follow-up yet of a controlled trial of MHFA. Furthermore, given the prevalence of mental disorders increases throughout adolescence [15], and adolescent participant age at 3-year follow-up would have been 16 years on average, there may have been greater opportunity for parents to engage in mental health first aid with their children, as compared to the earlier 1- and 2-year 
follow-ups. The primary aims were to evaluate the training's effect on the support parents offer their adolescent children with a mental health problem and the effect on adolescent mental health. Of secondary interest was whether improvements in mental health literacy were maintained over time.

\section{Methods}

\section{Study design}

Study methods have been described in detail elsewhere [14] but are briefly described here. The study was an RCT with participants randomized to Youth MHFA (YMHFA) or Red Cross Provide First Aid (PFA) training. It was registered with the Australian and New Zealand Clinical Trials Registry (ACTRN12612000390886).

\section{Participants and randomisation}

Participants were Australian parents of an adolescent aged 12-15 years, with one parent and adolescent registered as a dyad. The study was promoted via schools, the media and online. The trial website (www.tpot.net.au) provided information about the study and an online registration and consent form. Randomisation occurred during online registration using a random number generator programmed on the trial website. Two to three weeks after online registration, baseline interviews were conducted by a telephone survey company. These were conducted with both the parent and adolescent independently. Parents were informed of their randomisation at the end of the baseline interview. Blinding of parent participants to intervention was not possible, but telephone interviewers were blinded at each assessment. Recruitment occurred between October 2011 and March 2016.

\section{Interventions}

Accredited YMHFA or PFA instructors delivered the two face-to-face training courses to groups of parents in the community. Adolescents did not receive any training. Participants also received a course manual $[16,17]$.

\section{Youth Mental Health First Aid course}

The YMHFA training course is delivered to adults who work with or care for adolescents. The course teaches information about adolescent development, the signs and symptoms of the common and disabling mental health problems in young people, where and how to get help when a young person is developing a mental illness, what sort of help has been shown by research to be effective, and how to provide first aid in crisis situations. The course was taught across $4 \times 3.5 \mathrm{~h}$ sessions, usually run over two consecutive days.

\section{Red Cross Provide First Aid course}

The PFA training (HLTAID003) offers the skills and knowledge required to provide first aid response, life support, and casualty management until the arrival of medical or other assistance. Topics covered include cardiopulmonary resuscitation, drowning, anaphylaxis, airway obstruction, bleeding and wound care, head, neck and spinal injuries, poisoning, envenomation, seizure management, stroke and unconsciousness. The 15-h course was taught over 2 sessions.

\section{Outcomes}

Outcomes were assessed via computerized telephone interview at baseline and 1, 2, and 3-years later.

\section{Primary outcomes}

Adolescent mental health problem

Cases of a probable mental health problem were assessed by the 25-item Strengths and Difficulties Questionnaire (SDQ) [18] Parent and Child Report versions, adapted for phone interview. Total difficulties scores in the abnormal range ( $>=17$ for parent report and $>=20$ for adolescent self-report) indicated the presence of a probable mental health problem $[19,20]$.

\section{Perceptions of parent support by adolescents with a mental health problem}

This was assessed by asking adolescents the following questions: (1) "Over the last 12 months, have you had any sort of mental health problem?" If yes, (2) "What do you think the problem was?" (3) "Did you get help from family?", and (4) "How well did your mother/father support you when you had your mental health problem?" (asked about each adolescent's parent, as appropriate). Responses were "Very well", "Fairly well", "Not well", or "Unsure". If the adolescent was unsure what was meant by a "mental health problem", they were told "a period of weeks or more when you are feeling depressed, anxious, emotionally stressed, or are misusing alcohol or drugs, and these problems are interfering with your life". Responses were dichotomized into (1) "Very well" versus (0) "Fairly well", "Not well", or "Unsure".

\section{Quality of parental support towards adolescents with a mental health problem}

This was assessed by questions to the parent adapted from a previous survey [21]. (1) "Over the last 12 months has [your child] had any sort of mental health problem?" If yes, (2) "What do you think the problem was?", (3) "Over the last 12 months, have you done anything to help him/her with this mental health problem?", (4) "What did you do?". Open-ended responses to actions taken were scored blinded to group according to congruence with the MHFA Action Plan. Responses 
received a score of $0-2$ points for each component of the plan, with total scores ranging from 0 to 12 [22].

\section{Secondary outcomes}

The trial included a variety of secondary outcomes addressing mental health literacy, in common with other evaluations of MHFA [7] (see Table 1 for a description of each outcome measure). For parents, these included recognition of mental health problems, knowledge about youth mental health problems, confidence and intentions to help a person with a mental health problem, stigma towards people with mental health problems, and appropriate help-seeking for mental health problems. Some outcomes were in response to 4 hypothetical vignettes describing an adolescent with a mental health problem: depression, social phobia, an eating disorder not otherwise specified and psychosis [14]. In adolescents, secondary outcomes included perceived general social support from parents, intended and actual helpseeking from parents for a mental health problem, helpseeking from a health professional, and stigmatizing attitudes.

\section{Sample size estimation}

As reported in Morgan et al. [14], we required a sample size of 990 parent-adolescent dyads (495 per group). Based on 12-month prevalence data [26, 27], this sample size would include 128 adolescents with a mental health problem (64 in each group). This would allow us to detect an effect size of $d=0.44$, with a power $=0.80$ and an alpha $=0.05$, in the sub-sample of adolescents with a mental health problem.

\section{Adverse events}

There were no harms reported in this trial. Phone numbers for several services offering free 24-h telephone crisis or counselling support were provided to participants in case they felt distressed during the training or phone interviews and they were encouraged to advise the trial manager if they used these resources. A resource on suicide prevention was offered to adolescents aged 18 or older who were asked questions about suicide as part of the telephone interview.

\section{Ethics}

The study was approved by the University of Melbourne Human Research Ethics Committee.

\section{Statistical analysis}

Data were analyzed with mixed-effects models for continuous and binary outcome variables, with group by measurement occasion interactions. To help meet the missing at random assumption, parent age, tertiary education, and speaks only English at home were included as fixed effects in models analyzing parent outcomes. For continuous outcome measures with no substantial baseline imbalance, effect sizes (Cohen's d) were calculated by dividing the difference between the two group means at follow-up by their pooled standard deviation. With baseline imbalances, Cohen's d was calculated by dividing the mean change in each condition by the pooled standard deviation at follow-up. Effects were interpreted as small $=0.2$, medium $=0.5$ and large $=0.8$. Analyses were performed in Stata 15 and RStudio and the significance level was set at $p<.05$.

\section{Results}

\section{Participant flow and numbers analyzed}

The flow of participants throughout the trial is shown in Fig. 1. At 3-year follow-up there were 149 parents with interview data (46.3\% of baseline) and 118 adolescents (36.6\%). Logistic regression models explored predictors of missingness at 3-year follow-up. Parents were less likely to be missing if they had a tertiary education $(\mathrm{OR}=0.58,95 \% \mathrm{CI} 0.33$ to 0.95$)$, were younger in age $(\mathrm{OR}=0.95,95 \%$ CI 0.90 to 0.99$)$ and spoke only English at home $(\mathrm{OR}=0.38,95 \% \mathrm{CI} 0.19$ to 0.76$)$.

\section{Participant characteristics}

At baseline the two intervention groups showed similar sociodemographic characteristics (see Table 2). At the 3year follow-up, adolescents had a mean age of 16.5 (SD = $1.15)$ and slightly more than half were female $(n=82$, $55 \%)$. Only one parent had attended a MHFA course in the previous 12 months (in the MHFA group) and training in other mental health courses was rare $(3.2 \%$ of PFA group, $6.9 \%$ of MHFA group).

\section{Primary outcomes}

Table 3 shows the primary outcomes at baseline and 3year follow-up for the physical first aid and Youth Mental Health First Aid groups. There was a smaller proportion of adolescents with a mental health problem in the MHFA group than the PFA group at 3-year follow-up, based on both parent and child report on the SDQ, but the difference over time was not statistically significant.

Parents who reported their adolescent had a mental health problem generally scored low on the quality of mental health first aid support given to their child. Across follow-up, scores were higher in the MHFA group relative to the control, and although the MHFA group showed a small-to-medium sized improvement $(d=0.38)$ at 3-year follow-up, this change was not statistically significant. Unfortunately, parents gave truncated responses to the question of what they did to help their adolescent. Responses were only 16-17 words long on average with only superficial detail provided. 
Table 1 Overview of secondary outcomes

\begin{tabular}{|c|c|c|}
\hline Outcome & Survey measure & Response \\
\hline \multicolumn{3}{|c|}{ Outcomes completed by both parents and adolescents } \\
\hline $\begin{array}{l}\text { Social } \\
\text { Distance [23] }\end{array}$ & $\begin{array}{l}5 \text { questions assessing desire for } \\
\text { social distance from the person } \\
\text { in the psychosis vignette. } \\
\text { E.g. Would you be happy for your } \\
\text { child / Would you be happy ... to } \\
\text { develop a close friendship with X? }\end{array}$ & $\begin{array}{l}\text { 4-point Likert scale } \\
1=\text { Yes definitely } \\
2=\text { Yes, probably } \\
3=\text { Probably not } \\
4=\text { Definitely not }\end{array}$ \\
\hline $\begin{array}{l}\text { Stigma: Weak- } \\
\text { not-sick [23] }\end{array}$ & $\begin{array}{l}4 \text { questions assessing that the } \\
\text { person in the psychosis vignette is } \\
\text { weak not sick. } \\
\text { E.g. X could snap out of it if (he/she) } \\
\text { wanted }\end{array}$ & $\begin{array}{l}\text { 5-point Likert scale } \\
1=\text { Strongly disagree } \\
2=\text { Disagree } \\
3=\text { Neither agree nor disagree } \\
4=\text { Agree } \\
5=\text { Strongly agree }\end{array}$ \\
\hline $\begin{array}{l}\text { Stigma: } \\
\text { Dangerous/ } \\
\text { Unpredictable } \\
{[23]}\end{array}$ & $\begin{array}{l}4 \text { questions* assessing that the } \\
\text { person in the psychosis vignette is } \\
\text { dangerous or unpredictable. } \\
\text { E.g. X's problem makes (him/her) } \\
\text { unpredictable }\end{array}$ & $\begin{array}{l}5 \text {-point Likert scale } \\
1=\text { Strongly disagree } \\
2=\text { Disagree } \\
3=\text { Neither agree nor disagree } \\
4=\text { Agree } \\
5=\text { Strongly agree }\end{array}$ \\
\hline $\begin{array}{l}\text { K6 } \\
\text { psychological } \\
\text { distress (12- } \\
\text { month } \\
\text { version) [24] }\end{array}$ & $\begin{array}{l}6 \text { questions assessing the } \\
\text { frequency of psychological distress } \\
\text { in the worst month during the past } \\
12 \text { months }\end{array}$ & $\begin{array}{l}\text { 5-point Likert scale } \\
1=\text { None of the time } \\
2=\text { A little of the time } \\
3=\text { Some of the time } \\
4=\text { Most of the time } \\
5=\text { All of the time }\end{array}$ \\
\hline
\end{tabular}

Scoring

Mean score of 5 questions, range $1-4$.

Mean score of 4 questions, range $1-5$, dichotomized to low stigma $(=1)$ or not $(>1)$.

Parent $\omega=.81$ Adolescent $\omega=.56$

Mean score of 4 questions, range $1-5$.

Parent $\omega=.46$ Adolescent $\omega=.45$

Total scores of 19 or above indicate a high level of psychological distress

Parent $\omega=.91$ Adolescent $\omega=.93$

Verbatim responses were scored 1 point for correct recognition if the following were mentioned:

$\omega=0.82$

Depression (depression, depressed), social phobia (anxiety/anxious, social anxiety, social phobia, anxiety disorder, performance anxiety), EDNOS (Eating disorder, EDNOS, bulimia/bulimic/bulimia nervosa/ mia, binge eating/loss of control eating, binge eating disorder, anorexia/anorexia nervosa/anorexic/ ana, disordered eating), psychosis (schizophrenia/paranoid schizophrenia, psychosis/psychotic schizophrenic, schizoaffective disorder, precursor to schizophrenia). Mean score of 4 responses, range $0-1$.

Quality of MHFA Imagine $X$ is your child. You want to help (him/her). What would you do? intentions Question in response to each of 4 vignettes: depression, social phobia, EDNOS, psychosis

Confidence to How confident would you be in help your ability to help X? Question in response to each of 4 vignettes: depression, social phobia, EDNOS, psychosis

Knowledge about youth mental health problems

18 questions on knowledge about mental health problems, derived from the Youth MHFA manual [17]. E.g. If a teenager has a traumatic experience, it is best to make them talk about it as soon as possible
Verbatim responses were scored Mean score of 4 responses, range

for consistency with the MHFA $0-12$.

Action Plan in the Youth MHFA manual, [17] blinded to group allocation.

4-point Likert scale

$1=$ Very confident

$2=$ Fairly confident

$3=$ Slightly confident

$4=$ Not confident at al

Agree, Disagree, Don't know
Mean score of 4 responses, range $1-4$.

1 point for a correct response to each question, range 0-18.
Inter-rater reliability (ICC) for 4 vignettes ranged from

0.74-0.84.

$\omega=0.56$

$\omega=0.84$

Test-retest $r=$ 0.67 (PFA group) 
Table 1 Overview of secondary outcomes (Continued)

\begin{tabular}{|c|c|c|c|c|}
\hline Outcome & Survey measure & Response & Scoring & Psychometrics \\
\hline $\begin{array}{l}\text { Quality of } \\
\text { MHFA support } \\
\text { towards other } \\
\text { person }\end{array}$ & $\begin{array}{l}\text { Over the last } 12 \text { months, has anyone } \\
\text { else you know had any sort of mental } \\
\text { health problem?... Have you done } \\
\text { anything to help the person with } \\
\text { this problem?... What did you do? }\end{array}$ & $\begin{array}{l}\text { Verbatim responses were scored } \\
\text { for consistency with the MHFA } \\
\text { Action Plan, blinded to group } \\
\text { allocation. }\end{array}$ & Scores range $0-12$ & $\begin{array}{l}\text { Inter-rater } \\
\text { reliability } I C C= \\
0.76\end{array}$ \\
\hline $\begin{array}{l}\text { Appropriate } \\
\text { help-seeking } \\
\text { for mental } \\
\text { health } \\
\text { problem }\end{array}$ & $\begin{array}{l}\text { Over the last } 12 \text { months, have you } \\
\text { yourself had any sort of mental } \\
\text { health problem?... Have you done } \\
\text { anything to deal with this mental } \\
\text { health problem?... What did you do? }\end{array}$ & $\begin{array}{l}\text { Verbatim responses were scored } \\
\text { for the presence of an } \\
\text { appropriate source of help. }\end{array}$ & $\begin{array}{l}\text { Scored a } 1 \text { if mentioned any of the } \\
\text { following professionals or treatments: } \\
\text { taking medication, antidepressant, } \\
\text { anxiolytic, counselling, counsellor, GP, } \\
\text { psychologist, psychiatrist, CBT, hospital, } \\
\text { other medical (mental health } \\
\text { practitioner or specialist, professional } \\
\text { for alcohol misuse, maternal \& child } \\
\text { health nurse), professional organization } \\
\text { (Centre Against Sexual Assault, } \\
\text { Drummond Family Services). }\end{array}$ & \\
\hline \multicolumn{5}{|c|}{ Outcomes completed by adolescents only } \\
\hline $\begin{array}{l}\text { Perceived } \\
\text { general social } \\
\text { support from } \\
\text { parent [25] }\end{array}$ & $\begin{array}{l}\text { Communication subscale of Parent } \\
\text { Attachment from the People in My } \\
\text { Life Questionnaire ( } 5 \text { questions). } \\
\text { E.g. My parents can tell when I am } \\
\text { upset about something. }\end{array}$ & $\begin{array}{l}\text { 4-point Likert scale } \\
1=\text { Almost never or never true } \\
2=\text { Sometimes true } \\
3=\text { Often true } \\
4=\text { Almost always or always } \\
\text { true }\end{array}$ & Scores range 5-20. & $\omega=0.82$ \\
\hline $\begin{array}{l}\text { Intended } \\
\text { help-seeking } \\
\text { from parent }\end{array}$ & $\begin{array}{l}\text { If you had a problem right now like X } \\
\text { would you ask for help?... Where } \\
\text { would you go? } \\
\text { Question in response to each of } 4 \\
\text { vignettes: depression, social phobia, } \\
\text { EDNOS, psychosis }\end{array}$ & Verbatim responses. & $\begin{array}{l}\text { Scored } 1 \text { point per vignette if } \\
\text { mentioned seeking help from a parent. } \\
\text { Sum score of } 4 \text { responses, range } 0-4 \text {. }\end{array}$ & $\omega=0.71$ \\
\hline $\begin{array}{l}\text { Actual help- } \\
\text { seeking from } \\
\text { parent }\end{array}$ & $\begin{array}{l}\text { Over the last } 12 \text { months, have you } \\
\text { had any sort of mental health } \\
\text { problem?.. Did you get help from } \\
\text { family?... Who in the family? }\end{array}$ & Verbatim responses. & $\begin{array}{l}\text { Scored a } 1 \text { if adolescent reported } \\
\text { seeking help from either or both } \\
\text { parents. }\end{array}$ & \\
\hline $\begin{array}{l}\text { Help-seeking } \\
\text { from a health } \\
\text { professional }\end{array}$ & $\begin{array}{l}\text { Over the last } 12 \text { months, have you } \\
\text { had any sort of mental health } \\
\text { problem?... Did you get help from a } \\
\text { health professional or counsellor? }\end{array}$ & Verbatim responses. & $\begin{array}{l}\text { Scored a } 1 \text { if adolescent responded } \\
\text { with yes. }\end{array}$ & \\
\hline
\end{tabular}

Note: $\omega$ was calculated as Revelle's omega total for total scores

*3 questions only for adolescents, see Yap et al. 2014 [23]

Perceptions of support from parents by adolescents with a mental health problem were more positive in the MHFA group. However, the odds of improving between baseline and 3-year follow-up, relative to the control group, were not significant.

\section{Secondary outcomes}

The MHFA group showed small-to-medium improvements at 3-year follow-up relative to the control in two secondary outcomes: parental knowledge about youth mental health problems and adolescent perceptions of general social support from their parents (see Table 4). Of note, adolescent self-reported help-seeking for a mental health problem from their parent or a health professional was higher in the MHFA group than the PFA group, but the number of adolescents reporting a problem was very small (15 in PFA and 26 in MHFA) so the difference was not significant. Most other outcomes showed small or very small effects, which were not significant.

\section{Discussion}

This paper reports on the 3-year outcomes from Youth MHFA training as part of the Training for Parents of Teenagers randomized controlled trial. Overall, results at 3-year follow-up were similar to those observed at 1and 2-year follow-up [14]. Notwithstanding the limitations imposed by under-recruitment and high levels of attrition, the trial could not demonstrate clear benefits to the recipients of mental health first aid. Although effects were in the direction favoring MHFA training, the number of participants at follow-up was low, and the sub-sample reporting a mental health problem in adolescents even smaller. As with earlier follow-ups, there 


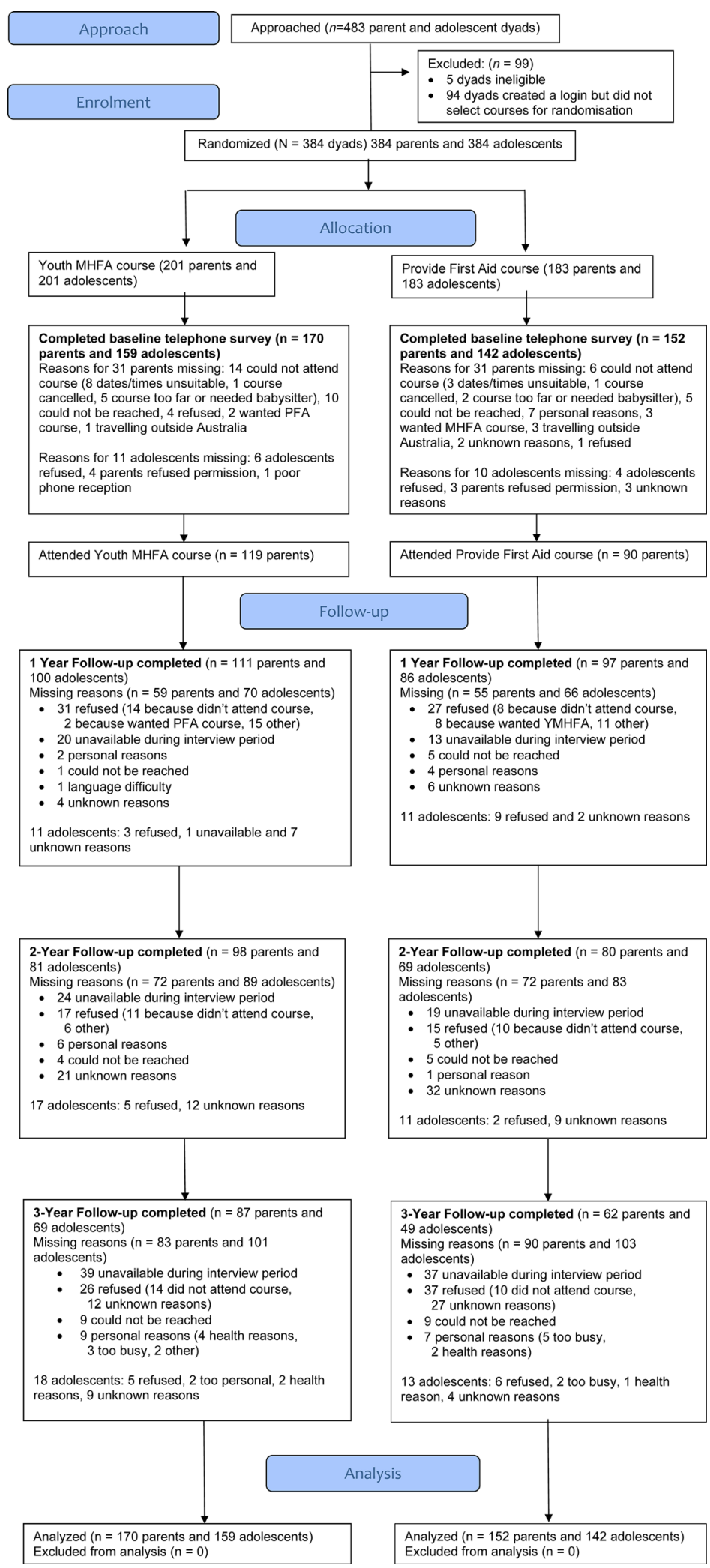

Fig. 1 CONSORT flow diagram 
Table 2 Baseline participant characteristics

\begin{tabular}{|c|c|c|c|}
\hline & YMHFA $(n=170)$ & $\begin{array}{l}\text { PFA } \\
(n=152)\end{array}$ & $\begin{array}{l}\text { TOTAL } \\
(n=322)\end{array}$ \\
\hline \multicolumn{4}{|l|}{ Parent } \\
\hline \multicolumn{4}{|l|}{ Family situation \% } \\
\hline Child living with both parents & 71.8 & 75.7 & 73.6 \\
\hline Parents separated but both involved in care of child & 12.9 & 9.2 & 11.2 \\
\hline Parents separated but only respondent involved in care of child & 7.1 & 5.3 & 6.2 \\
\hline Sole parent & 6.5 & 6.6 & 6.5 \\
\hline Other (e.g. grandparents) & 1.8 & 3.3 & 2.5 \\
\hline Married/defacto \% & 74.1 & 80.9 & 77.3 \\
\hline Female \% & 89.4 & 86.8 & 88.2 \\
\hline Tertiary education \% & 56.6 & 50.7 & 53.8 \\
\hline Speaks only English at home \% & 85.9 & 79.6 & 82.9 \\
\hline Not Aboriginal or Torres Strait Islander \% & 99.4 & 98.7 & 99.1 \\
\hline Employed full or part time \% & 66.5 & 71.7 & 68.9 \\
\hline \multicolumn{4}{|l|}{ Studying status \% } \\
\hline Full-time & 2.9 & 3.9 & 3.4 \\
\hline Part-time & 16.5 & 11.2 & 14.0 \\
\hline Not studying & 11.2 & 18.4 & 14.6 \\
\hline Unknown & 69.4 & 66.4 & 68.0 \\
\hline Age M (SD) & $45.2(5.54)$ & $45.1(5.69)$ & $45.2(5.60)$ \\
\hline Number of children M (SD) & $2.2(0.8)$ & $2.3(1.0)$ & $2.2(0.9)$ \\
\hline \multicolumn{4}{|l|}{ Child } \\
\hline Female \% & 58.8 & 52.0 & 55.6 \\
\hline Health issue \% & 26.5 & 27.0 & 26.7 \\
\hline Age M (SD) & $13.3(1.11)$ & $13.3(1.08)$ & $13.3(1.09)$ \\
\hline
\end{tabular}

remained a lack of statistical power at 3-year follow-up. Even though there were higher rates of adolescents with mental health problems at 3-year follow-up (reflecting the higher risk period of middle-to-late adolescence), there was more attrition compared to 1- and 2-year follow-up [14]. There were few improvements in study outcomes observable 3 years after training, apart from parents' knowledge of youth mental health problems and adolescents' perceptions of general social support from their parents. Improved parent mental health knowledge was the largest effect demonstrated at 1- and 2-year follow-up, and this was sustained at 3-year follow-up. The effect on adolescents' perceptions of general support from parents was stronger at 3 years compared to earlier timepoints, but it is possible this is a chance finding, given the large number of outcomes analyzed. Most other mental health literacy effects had faded and were too small to detect with our sample size.

The results from this study support the need for refresher MHFA training to maintain knowledge and skills. Refresher courses in Youth, Standard (adult) and Aboriginal and Torres Strait Islander MHFA are now offered by Mental Health First Aid Australia. These are 4-h face-to-face courses for those who have completed training in the last 3 years. The Refresher Courses are designed to update knowledge and skills and include a focus on attendees' experiences providing mental health first aid, barriers and facilitators to providing aid, and knowing when to approach someone. In line with physical first aid accreditation, completion of refresher courses can extend MHFA accreditation for a further 3 years. Refresher Courses have not yet been evaluated, but Mental Health First Aid Australia plans to do so as part of its research strategy.

Future research should investigate other ways of testing whether MHFA training benefits the recipient of aid, in designs where the trainee and aid recipient can be participants in the study. One approach is to train employees in an organization, who can serve as both trainees and potential recipients of aid from co-workers. The EMPOWER study is currently being conducted by the Centre for Mental Health and London South Bank University in the United Kingdom. This study will provide MHFA training to selected staff in workplaces and 
Table 3 Primary outcomes at baseline and 3-year follow-up for Physical First Aid and Youth Mental Health First Aid groups

\begin{tabular}{|c|c|c|c|c|c|c|c|c|c|c|c|c|c|c|c|c|c|}
\hline & \multirow{2}{*}{\multicolumn{4}{|c|}{ Baseline }} & \multirow{2}{*}{\multicolumn{4}{|c|}{ 1-year follow-up }} & \multirow{2}{*}{\multicolumn{4}{|c|}{ 2-year follow-up }} & \multirow{2}{*}{\multicolumn{4}{|c|}{ 3-year follow-up }} & \multirow{4}{*}{$\begin{array}{l}\text { Change over time } \\
\text { between YMHFA } \\
\text { and PFA } \\
\text { Baseline to 3-year } \\
\text { follow-up } \\
\text { OR (95\% Cl) }\end{array}$} \\
\hline & & & & & & & & & & & & & & & & & \\
\hline & \multicolumn{2}{|l|}{ PFA } & \multicolumn{2}{|l|}{ YMHFA } & \multicolumn{2}{|c|}{ PFA } & \multicolumn{2}{|l|}{ YMHFA } & \multicolumn{2}{|c|}{ PFA } & \multicolumn{2}{|c|}{ YMHFA } & \multicolumn{2}{|c|}{ PFA } & \multicolumn{2}{|c|}{ YMHFA } & \\
\hline & $n / N$ & $\%$ & $\mathrm{n} / \mathrm{N}$ & $\%$ & $n / N$ & $\%$ & $\mathrm{n} / \mathrm{N}$ & $\%$ & $n / N$ & $\%$ & $\mathrm{n} / \mathrm{N}$ & $\%$ & $n / N$ & $\%$ & $\mathrm{n} / \mathrm{N}$ & $\%$ & \\
\hline $\begin{array}{l}\text { Adolescent with mental } \\
\text { health problem - parent } \\
\text { reported }^{\mathrm{a}}\end{array}$ & 19/151 & 12.6 & $31 / 168$ & 18.5 & $8 / 96$ & 8.33 & $15 / 109$ & 13.8 & $10 / 80$ & 12.5 & $14 / 98$ & 14.3 & $6 / 61$ & 9.8 & $6 / 86$ & 7.0 & 0.17 (0.01 to 1.98$)$ \\
\hline $\begin{array}{l}\text { Adolescent with mental } \\
\text { health problem - } \\
\text { adolescent reported }^{\mathrm{b}}\end{array}$ & $11 / 142$ & 7.75 & 20/159 & 12.6 & $6 / 86$ & 6.98 & $12 / 100$ & 12.0 & $5 / 69$ & 7.25 & $5 / 81$ & 6.17 & $5 / 49$ & 10.2 & $4 / 69$ & 5.8 & $0.16(0.02$ to 1.41$)$ \\
\hline $\begin{array}{l}\text { Mother supported } \\
\text { adolescent very well }\end{array}$ & $14 / 26$ & 53.9 & $17 / 30$ & 56.7 & $6 / 10$ & 60.0 & $8 / 22$ & 36.4 & $2 / 11$ & 18.2 & $8 / 20$ & 40.0 & $4 / 15$ & 26.7 & $10 / 23$ & 43.5 & 2.80 (0.11 to 72.56$)$ \\
\hline \multirow{3}{*}{$\begin{array}{l}\text { Father supported } \\
\text { adolescent very well }\end{array}$} & $7 / 23$ & 30.4 & $7 / 29$ & 24.1 & $3 / 8$ & 37.5 & $2 / 21$ & 9.52 & $2 / 10$ & 20.0 & $5 / 19$ & 26.3 & $3 / 15$ & 20.0 & $8 / 24$ & 33.3 & 4.31 (0.31 to 60.68$)$ \\
\hline & \multicolumn{2}{|l|}{$\begin{array}{l}\text { PFA }(n= \\
38)\end{array}$} & \multicolumn{2}{|c|}{$\begin{array}{l}\text { MHFA }(n= \\
54)\end{array}$} & \multicolumn{2}{|c|}{$\begin{array}{l}\text { PFA }(n= \\
\text { 24) }\end{array}$} & \multicolumn{2}{|c|}{$\begin{array}{l}\text { MHFA }(n= \\
28)\end{array}$} & \multicolumn{2}{|c|}{$\begin{array}{l}\text { PFA }(n= \\
18)\end{array}$} & \multicolumn{2}{|c|}{$\begin{array}{l}\text { MHFA }(n= \\
34)\end{array}$} & \multicolumn{2}{|c|}{$\begin{array}{l}\text { PFA }(n= \\
19)\end{array}$} & \multicolumn{2}{|c|}{$\begin{array}{l}\text { MHFA }(n= \\
35)\end{array}$} & $\begin{array}{l}\text { Baseline to 3-year } \\
\text { follow-up }\end{array}$ \\
\hline & M & SD & $M$ & SD & $M$ & SD & $M$ & SD & M & SD & $M$ & SD & M & SD & $M$ & SD & $\begin{array}{l}M_{\text {diff }}(95 \% \mathrm{Cl}), d \\
(95 \% \mathrm{Cl})\end{array}$ \\
\hline $\begin{array}{l}\text { Quality of parental } \\
\text { support towards } \\
\text { adolescents with } \\
\text { mental health problem }\end{array}$ & 2.55 & 1.18 & 2.41 & 1.19 & 2.29 & 1.08 & 2.46 & 1.00 & 2.61 & 1.09 & 2.82 & 1.45 & 2.32 & 0.95 & 2.77 & 1.33 & $\begin{array}{l}0.41(-0.38 \text { to } 1.20) \text {, } \\
0.38(-0.18 \text { to } 0.94)\end{array}$ \\
\hline
\end{tabular}

examine employee experiences of providing and receiving aid, as well as effects on mental health and economic impacts [28]. Although mental health first aid provided within a workplace setting may not generalize to other settings or relationships, a workplace setting can provide objective data on sickness rates and productivity and allows for an examination of changes in organizational culture. Another way to evaluate the effect of MHFA training on aid recipients includes training school staff in Youth MHFA and examining the impact on student help-seeking and mental health. This design allows for the collection of objective data on referral rates to school counselling services, which avoids relying on student self-reports of help received from others, which was assessed in a previous school-based trial [29]. A similar approach would be to train young people in university or college settings, who could then provide support to college peers, and data on help-seeking could be obtained from college counselling services (e.g. [30]).

Another issue for future research on MHFA is how to capture quality data on changes in mental health first aid skills. This study used open-ended responses to collect data on intentions to give aid and descriptions of aid provided. These responses were then scored against the MHFA Action Plan. As reported above, most of the descriptions given by parent participants were very brief and superficial in detail and therefore corresponded to low scores. The experience from this trial and others (e.g. [31, 32]) shows that this method may not capture the full extent of the action participants took, making it difficult to show changes over time. An alternative is to present a list of potential actions for participants to select from, including actions consistent with MHFA training and plausible but inconsistent actions, such as has been used in suicide prevention research [33]. This approach would mean all aspects of the MHFA Action Plan could be assessed and it would avoid the problem of truncated and superficial responses. Repeated brief assessments at shorter intervals than 1-year follow-up would also minimize the impact of memory on recollecting supportive or helpful behaviours offered.

This study's key strengths were its long follow-up period to assess the lasting impact of any training effects, the active control condition to control for receiving health education training, and involvement of both parents and adolescents to assess training effects upon aid recipients. Notwithstanding these strengths, the study had some significant limitations. There was a high degree of attrition over time, which limited power to detect training effects. Attrition at follow-up was partly due to a lack of interest in the study from parents who did not attend their allocated course. These were a significant minority and more frequent in the control group. Furthermore, using an independent survey company to contact participants at follow-up may have reduced the potential for successful cohort maintenance by the 
Table 4 Secondary outcomes at baseline and 3-year follow-up for Physical First Aid and Youth Mental Health First Aid groups

\begin{tabular}{|c|c|c|c|c|c|c|c|c|c|c|c|c|c|}
\hline \multirow[b]{3}{*}{ Variable } & \multicolumn{6}{|c|}{ Baseline } & \multicolumn{6}{|c|}{ 3-year follow-up } & \multirow{3}{*}{$\begin{array}{l}\text { Change over time between } \\
\text { MHFA and PFA } \\
\text { Baseline to 3-year follow-up } \\
M_{\text {diff }}(95 \% \mathrm{Cl}) \\
d^{\#}(95 \% \mathrm{Cl})\end{array}$} \\
\hline & \multicolumn{3}{|l|}{ PFA } & \multicolumn{3}{|c|}{ MHFA } & \multicolumn{3}{|c|}{ PFA } & \multicolumn{3}{|c|}{ MHFA } & \\
\hline & $\mathbf{n}$ & M & SD & $\mathbf{n}$ & $M$ & SD & $\mathbf{n}$ & M & SD & $\mathbf{n}$ & M & SD & \\
\hline MHFA knowledge & 152 & 9.77 & 2.76 & 170 & 10.28 & 2.71 & 62 & 9.95 & 2.62 & 86 & 12.00 & 2.13 & $0.96(0.26 \text { to } 1.66)^{* *}, 0.31(-0.02$ to 0.63$)$ \\
\hline Problem recognition & 152 & 0.63 & 0.35 & 170 & 0.66 & 0.31 & 62 & 0.76 & 0.28 & 86 & 0.86 & 0.23 & $0.03(-0.05$ to 0.11$), 0.07(-0.25$ to 0.40$)$ \\
\hline Quality of MHFA intentions & 152 & 2.24 & 0.62 & 170 & 2.34 & 0.73 & 62 & 2.29 & 0.78 & 86 & 2.58 & 0.84 & 0.12 ( -0.15 to 0.39$), 0.09$ ( -0.23 to 0.42$)$ \\
\hline Confidence & 151 & 2.25 & 0.68 & 169 & 2.36 & 0.61 & 62 & 2.13 & 0.72 & 86 & 2.08 & 0.59 & $-0.11(-0.29$ to 0.08$), 0.01$ ( -0.32 to 0.33 ) \\
\hline $\begin{array}{l}\text { Quality of MHFA support towards } \\
\text { other person }\end{array}$ & 86 & 2.23 & 1.16 & 113 & 2.29 & 1.14 & 34 & 2.18 & 1.34 & 58 & 2.47 & 1.14 & $0.21(-0.35$ to 0.76$), 0.24(-0.19$ to 0.66$)$ \\
\hline Social distance (parent) & 145 & 2.16 & 0.66 & 160 & 2.08 & 0.63 & 61 & 1.89 & 0.67 & 85 & 1.79 & 0.58 & $0.05(-0.12$ to 0.21$),-0.05(-0.38$ to 0.29$)$ \\
\hline $\begin{array}{l}\text { Dangerous/ unpredictable stigma } \\
\text { (parent) }\end{array}$ & 147 & 2.48 & 0.52 & 164 & 2.44 & 0.56 & 61 & 2.31 & 0.60 & 85 & 2.26 & 0.56 & $0.03(-0.16$ to 0.21$),-0.09(-0.41$ to 0.24$)$ \\
\hline Social distance (adolescent) & 140 & 2.23 & 0.61 & 157 & 2.20 & 0.66 & 47 & 2.22 & 0.64 & 69 & 2.18 & 0.60 & $-0.06(-0.25$ to 0.13$), 0.10$ ( -0.28 to 0.47$)$ \\
\hline Weak not sick stigma (adolescent) & 142 & 2.33 & 0.65 & 157 & 2.29 & 0.75 & 48 & 1.62 & 0.58 & 69 & 1.54 & 0.63 & $0.08(-0.15$ to 0.30$),-0.24(-0.61$ to 0.13$)$ \\
\hline $\begin{array}{l}\text { Dangerous/ unpredictable stigma } \\
\text { (adolescent) }\end{array}$ & 133 & 2.63 & 0.67 & 148 & 2.56 & 0.67 & 48 & 2.56 & 0.52 & 65 & 2.46 & 0.67 & $-0.08(-0.31$ to 0.14$), 0.19(-0.20$ to 0.57$)$ \\
\hline $\begin{array}{l}\text { Perceived general social support } \\
\text { from parent }\end{array}$ & 142 & 16.26 & 3.11 & 159 & 15.74 & 3.50 & 49 & 14.37 & 3.30 & 69 & 15.48 & 3.28 & $1.15(0.09 \text { to } 2.21)^{*}, 0.35$ (-0.02 to 0.72$)$ \\
\hline \multirow{2}{*}{$\begin{array}{l}\text { Adolescent intended help-seeking } \\
\text { from parent }\end{array}$} & 140 & 2.71 & 1.18 & 158 & 2.38 & 1.27 & 48 & 2.69 & 1.36 & 69 & 2.46 & 1.43 & $0.03(-0.43$ to 0.48$), 0.03(-0.34$ to 0.40$)$ \\
\hline & n & $\%$ & & $\mathbf{n}$ & $\%$ & & $\mathrm{n}$ & $\%$ & & $\mathbf{n}$ & $\%$ & & OR $(95 \% \mathrm{CI})$ \\
\hline $\begin{array}{l}\text { Weak not sick stigma (parent) - } \\
\text { median or below }\end{array}$ & 87 & 57.6 & & 95 & 56.6 & & 46 & 74.2 & & 70 & 81.4 & & $1.06(0.29$ to 3.83$)$ \\
\hline K6 above cut-off (parent) & 28 & 18.5 & & 37 & 21.9 & & 12 & 19.7 & & 13 & 15.1 & & 0.38 (0.09 to 1.69$)$ \\
\hline K6 above cut-off (adolescent) & 33 & 23.4 & & 42 & 26.6 & & 16 & 33.3 & & 21 & 30.4 & & 0.71 (0.17 to 3.02 ) \\
\hline $\begin{array}{l}\text { Parent sought appropriate help for } \\
\text { own mental health problem }\end{array}$ & 36 & 81.8 & & 49 & 69.0 & & 12 & 75.0 & & 24 & 75.0 & & $10.24(0.27$ to 384.71$)$ \\
\hline $\begin{array}{l}\text { Adolescent sought help from } \\
\text { parent for mental health problem }\end{array}$ & 22 & 75.9 & & 24 & 77.4 & & 6 & 40.0 & & 17 & 65.4 & & 4.69 (0.36 to 61.64$)$ \\
\hline $\begin{array}{l}\text { Adolescent sought help from health } \\
\text { professional for mental health problem }\end{array}$ & 19 & 65.5 & & 23 & 74.2 & & 9 & 60.0 & & 19 & 73.1 & & 1.16 (0.15 to 8.87$)$ \\
\hline
\end{tabular}

${ }^{*} p<.05,{ }^{* *} p<.01$

\# Positive Cohen's d favors MHFA and negative $d$ favors PFA

$M$ Mean, SD Standard deviation

research team. Finally, one of our primary outcome measures, cases of adolescent mental health problems, may have been too far downstream to be a realistic outcome to measure. MHFA is not designed to prevent or treat mental health problems, and improvements in the mental health of aid recipients depends on the quality of professional help received. Focusing on intermediary steps, such as rates of professional help-seeking, may be a more suitable primary outcome measure to assess in future trials of MHFA.

\section{Conclusions}

Three years after training, participants had maintained their improved knowledge about youth mental health problems. There were some indications of positive effects upon adolescent mental health and parental support given to adolescents with a mental health problem, but the study was underpowered to clearly show benefits to mental health first aid skills and recipients of aid.

\section{Abbreviations}

EDNOS: Eating Disorder Not Otherwise Specified; MHFA: Mental Health First Aid; OSFED: Other Specified Feeding and Eating Disorder; PFA: Provide First Aid; SDQ: Strengths and Difficulties Questionnaire; YMHFA: Youth Mental Health First Aid

\section{Acknowledgements}

We would like to thank Anna Ross for assistance with coding open-ended responses.

\section{Authors' contributions}

$A J, B K, C K, L H, M Y$, and NR contributed to the study design. JF was the project manager and coded open-ended responses. LH and CK presented some of the YMHFA training courses as accredited instructors. AM carried out the data analysis and drafted the manuscript. All other authors suggested improvements and approved the final manuscript. 


\section{Funding}

The trial was funded by the National Health and Medical Research Council (APP1042772), which played no role in the design of the study, data collection, analysis, interpretation of data or writing of the manuscript. AJ (APP1059785), NR (APP1083394) and MY (APP1061744) were supported by National Health and Medical Research Council Fellowships. AM is supported by a C.R. Roper Fellowship.

\section{Availability of data and materials}

Requests for access to the data should be made to the first author.

\section{Ethics approval and consent to participate}

Participants gave online written consent to participate at the beginning of the study and verbal consent to participate at each follow-up assessment interview. The study was approved by the University of Melbourne Human Research Ethics Committee (Ethics ID 1135679).

\section{Consent for publication}

Not applicable.

\section{Competing interests}

CK, BK and AJ are the authors of the Youth MHFA course. CK is employed by MHFA International (trading as MHFA Australia) as the Director of Research and Curriculum, $\mathrm{AJ}$ is a member of the Board and BK a former CEO and member of the Board of this organization. AM, JF, NR, MY, and LH have no competing interests.

\section{Author details}

'Centre for Mental Health, Melbourne School of Population and Global Health, University of Melbourne, 207 Bouverie Street, Melbourne, Victoria 3010, Australia. 'School of Psychology and Public Health, La Trobe University, Melbourne, Australia. ${ }^{3}$ Mental Health First Aid Australia, Parkville, Australia. ${ }^{4}$ School of Psychology, Faculty of Health, Deakin University, Burwood, Australia. ${ }^{5}$ School of Psychological Sciences, Turner Institute for Brain and Mental Health, Monash University, Clayton, Australia.

\section{Received: 29 April 2020 Accepted: 8 September 2020}

\section{Published online: 06 October 2020}

\section{References}

1. Kitchener BA, Jorm AF. Mental health first aid: an international programme for early intervention. Early Interv Psychiatry. 2008;2(1):55-61.

2. Which courses are available [https://mhfa.com.au/courses]. Accessed $16 \mathrm{Mar}$ 2020

3. International MHFA Programs [https://mhfa.com.au/our-impact/ international-mhfa-programs]. Accessed 16 Mar 2020

4. Jorm AF, Kitchener BA, Reavley NJ. Mental health first aid training: lessons learned from the global spread of a community education program. World Psychiatry. 2019;18(2):142-3.

5. Jorm AF, Ross AM. Guidelines for the public on how to provide mental health first aid: narrative review. BJPsych Open. 2018;4(6):427-40.

6. Bond KS, Cottrill FA, Blee FL, Kelly CM, Kitchener BA, Jorm AF. Offering mental health first aid to a person with depression: A Delphi study to redevelop the guidelines published in 2008. BMC Psychology. 2019;7(1):37.

7. Morgan AJ, Ross A, Reavley NJ. Systematic review and meta-analysis of Mental Health First Aid training: Effects on knowledge, stigma, and helping behaviour. PLoS One 2018:13(5):e0197102

8. Jorm AF, Kitchener BA, O'Kearney R, Dear KBG. Mental health first aid training of the public in a rural area: a cluster randomized trial [ISRC TN53887541]. BMC Psychiatry. 2004;4(1):33.

9. Massey J, Brooks M, Burrow J. Evaluating the effectiveness of mental health first aid training among student affairs staff at a Canadian university. J Stud Aff Res Pract. 2014;51(3):323-36

10. Svensson B, Hansson L. Effectiveness of Mental Health First Aid training in Sweden. A randomized controlled trial with a six-month and two-year follow-up. PLoS One. 2014:9(6):e100911.

11. Maslowski AK. Effectiveness of mental health first aid: a meta-analysis. Ment Health Rev J. 2019;24(4):245-61.

12. Richardson R, Dale HE, Wellby G, McMillan D, Churchill R. Mental Health First Aid as a tool for improving mental health and well-being. Cochrane Database Syst Rev. 2018;(9):CD013127.
13. Kessler RC, Angermeyer M, Anthony JC, De Graaf R, Demyttenaere K, Gasquet I, De Girolamo G, Gluzman S, Gureje O, Haro JM. Lifetime prevalence and age-of-onset distributions of mental disorders in the World Health Organization's world mental health survey initiative. World Psychiatry. 2007;6(3):168.

14. Morgan AJ, Fischer J-A, Hart LM, Kelly CM, Kitchener BA, Reavley NJ, Yap $\mathrm{MBH}$, Cvetkovski S, Jorm AF. Does mental health first aid training improve the mental health of aid recipients? The training for parents of teenagers randomised controlled trial. BMC Psychiatry. 2019;19:99.

15. Merikangas KR, He J-P, Burstein M, Swanson SA, Avenevoli S, Cui L, Benjet C, Georgiades K, Swendsen J. Lifetime prevalence of mental disorders in U.S. adolescents: results from the National Comorbidity Survey ReplicationAdolescent Supplement (NCS-A). J Am Acad Child Adolesc Psychiatry. 2010; 49(10):980-9.

16. Haines J. Emergency first aid. APL Healthcare: Rowville, Victoria; 2012.

17. Kelly CM, Kitchener BA, Jorm AF. Youth mental health first aid: a manual for adults assisting young people. 3rd ed. Melbourne, Australia: Mental Health First Aid Australia; 2013.

18. Goodman R. Psychometric properties of the strengths and difficulties questionnaire. J Am Acad Child Adolesc Psychiatry. 2001;40(11):1337-45.

19. Goodman R. The strengths and difficulties questionnaire: a research note. J Child Psychol Psychiatry. 1997:38:6.

20. Scoring the Strengths \& Difficulties Questionnaire for age 4-17 [http://www sdqinfo.com/py/sdqinfo/c0.py]. Accessed 19 Jan 2011.

21. Yap MBH, Wright A, Jorm AF. First aid actions taken by young people for mental health problems in a close friend or family member: findings from an Australian national survey of youth. Psychiatry Res. 2011;188:123-8.

22. Rossetto A, Jorm AF, Reavley NJ. Quality of helping behaviours of members of the public towards a person with a mental illness: a descriptive analysis of data from an Australian national survey. Ann General Psychiatry. 2014;13:2.

23. Yap MBH, Mackinnon AJ, Reavley NJ, Jorm AF. The measurement properties of stigmatising attitudes towards mental disorders: results from two community surveys. Int J Methods Psychiatr Res. 2014:23(1):49-61.

24. Kessler RC, Green JG, Gruber MJ, Sampson NA, Bromet E, Cuitan M, Furukawa TA, Gureje O, Hinkov H, Hu CY, et al. Screening for serious mental illness in the general population with the $\mathrm{K} 6$ screening scale: results from the WHO world mental health (WMH) survey initiative. Int J Methods Psychiatr Res. 2010;19(Suppl 1):4-22.

25. Ridenour TA, Greenberg MT, Cook ET. Structure and validity of people in my life: a self-report measure of attachment in late childhood. J Youth Adolesc. 2006;35(6):1037-53.

26. Australian Bureau of Statistics. National survey of mental health and wellbeing: summary of results, vol. Catalogue no. 4326.0. Canberra: ABS; 2007

27. Jorm AF, Wright A, Morgan AJ. Where to seek help for a mental disorder? A national survey of the beliefs of Australian youth and their parents. Med J Aust. 2007:187:556-60.

28. Free Mental Health First Aid training for your workplace [https://www centreformentalhealth.org.uk/free-mental-health-first-aid-training-yourworkplace]. Accessed 16 Mar 2020.

29. Jorm AF, Kitchener BA, Sawyer MG, Scales H, Cvetkovski S. Mental health first aid training for high school teachers: a cluster randomized trial. BMC Psychiatry. 2010;10(1):51.

30. Lipson SK, Speer N, Brunwasser S, Hahn E, Eisenberg D. Gatekeeper training and access to mental health care at universities and colleges. J Adolesc Health. 2014:55(5):612-9.

31. Reavley NJ, Morgan AJ, Fischer J-A, Kitchener BA, Bovopoulos N, Jorm AF. Effectiveness of eLearning and blended modes of delivery of mental health first aid training in the workplace: randomised controlled trial. BMC Psychiatry. 2018:18:312

32. Hart LM, Mason RJ, Kelly CM, Cvetkovski S, Jorm AF. 'teen mental health first aid': a description of the program and an initial evaluation. Int J Ment Health Syst. 2016;10(1):3

33. Jorm AF, Nicholas A, Pirkis J, Rossetto A, Reavley NJ. Associations of training to assist a suicidal person with subsequent quality of support: results from a national survey of the Australian public. BMC Psychiatry. 2018;18(1):132.

\section{Publisher's Note}

Springer Nature remains neutral with regard to jurisdictional claims in published maps and institutional affiliations. 